\title{
Molecular effects of novel mutations in HesX1/HESX1 associated with human
} pituitary disorders

\author{
Joshua M. Brickman ${ }^{1, \star}, \neq$, Melanie Clements ${ }^{1}$, Richard Tyrell ${ }^{2}$, David McNay ${ }^{3}$, Kathryn Woods ${ }^{3}$, \\ Justin Warner ${ }^{4}$, Andrew Stewart ${ }^{1}$, Rosa S. P. Beddington ${ }^{1}$ and Mehul Dattani ${ }^{1,3, \neq}$ \\ ${ }^{1}$ Division of Mammalian Development, ${ }^{2}$ Division of Protein Structure, National Institute for Medical Research, The Ridgeway, \\ London NW7 1AA, UK \\ ${ }^{3}$ Institute of Child Health, 30 Guilford Street, London WC1N 1EH, UK \\ ${ }^{4}$ Department of Paediatric Endocrinology, John Radcliffe Hospital, Headley Way, Headington, Oxford OX3 9DU, UK \\ *Present address: Centre for Genome Research, The University of Edinburgh, Kings Buildings, West Mains Road, Edinburgh EH9 3JQ, UK \\ ¥Authors for correspondence (e-mail: Josh.Brickman@ed.ac.uk and M.Dattani@ich.ucl.ac.uk)
}

Accepted 10 October 2001

\section{SUMMARY}

The homeobox gene Hesx1/HESX1 has been implicated in the establishment of anterior pattern in the central nervous system $(\mathrm{CNS})$ in a number of vertebrate species. Its role in pituitary development has been documented through lossof-function studies in the mouse. A homozygous missense point mutation resulting in a single amino acid substitution, Arg160Cys (R160C), is associated with a heritable form of the human condition of septo-optic dysplasia (SOD). We have examined the phenotype of affected members in this pedigree in more detail and demonstrate for the first time a genetic basis for midline defects associated with an undescended or ectopic posterior pituitary. A similar structural pituitary abnormality was observed in a second patient heterozygous for another mutation in HESX1, Ser170Leu (S170L). Association of S170L with a pituitary phenotype may be a direct consequence of the HESXI mutation since S170L is also associated with a dominant familial form of pituitary disease. However, a third mutation in HESX1, Asn125Ser (N125S), occurs at a high frequency in the Afro-Caribbean population and may therefore reflect a population-specific polymorphism. To investigate the molecular basis for these clinical phenotypes, we have examined the impact of these mutations on the regulatory functions of HESX1. We show

\section{INTRODUCTION}

The elaborate spatial and temporal patterns of gene expression generated during vertebrate embryogenesis are mediated by a large array of transcription factors. Homeodomain proteins constitute a major class of transcription factors responsible for this refined program of embryonic gene expression [reviewed by Duboule (Duboule 1994)]. Members of this family are characterised by the possession of a tripartite helical homeodomain, which recognises the core binding site TAAT that Hesx1 is a promoter-specific transcriptional repressor with a minimal 36 amino acid repression domain which can mediate promoter-specific repression by suppressing the activity of homeodomain-containing activator proteins. Mutations in HESX1 associated with pituitary disease appear to modulate the DNA-binding affinity of HESX1 rather than its transcriptional activity. Wild-type HESX1 binds a dimeric homeodomain site with high affinity $\left(K_{\mathrm{d}} 31\right.$ nM) whilst HESX1(S170L) binds with a 5-fold lower activity $\left(K_{\mathrm{d}} 150 \mathrm{nM}\right)$ and HESX1(R160C) does not bind at all. Although HESX1(R160C) has only been shown to be associated with the SOD phenotype in children homozygous for the mutation, HESX1(R160C) can inhibit DNA binding by wild-type HESX1 both in vitro and in vivo in cell culture. This dominant negative activity of HESX1(R160C) is mediated by the Hesx1 repression domain, supporting the idea that the repression domain is implicated in interactions between homeodomain proteins. Our data suggest a possible molecular paradigm for the dominant inheritance observed in some pituitary disorders.

Key words: Repression, Homeodomain, Pituitary, Hesx1/HESX1, Transcription and mediates the primary component of homeodomain protein functional specificity [reviewed by Gehring (Gehring et al., 1994)]. Further specificity in homeodomain-DNA interactions is generated by the ninth residue in the third helix of the homeodomain, which binds the two bases immediately $3^{\prime}$ to this core (Schier and Gehring, 1992; Treisman et al., 1989; Wilson et al., 1993). However, the broad classes of specificity generated by recognition of the TAAT core and its flanking sequences does little to define specific DNA sequences recognised by individual homeodomain proteins (Desplan et 
al., 1988; Gehring et al., 1994). Consequently homeodomain functional specificity must be generated by protein-protein interactions including dimerization and/or cooperative DNA binding [reviewed by Wolberger (Wolberger, 1996)].

The Paired (prd) class of homeodomain proteins binds to DNA cooperatively as dimers (Wilson et al., 1993). Some members of this family are characterised by the possession of an additional DNA-binding domain (the Prd domain), e.g. Drosophila prd and the Pax genes, while other members of this family contain only a prd class homeodomain, e.g. Hesx1, Goosecoid (Gsc). The prd homeodomain is known to bind cooperatively to adjacent TAAT cores and the spacing between cores preferred by specific prd domain proteins also depends on the ninth residue of helix three of the homeodomain.

The prd homeodomain protein HESX1 (also know as Rpx) was recently implicated in the human disease Septo-Optic Dysplasia (SOD) (Dattani et al., 1998). Hesxl is expressed early in mouse development, beginning with a small patch of cells in the anterior midline visceral endoderm (Hermesz et al., 1996; Thomas and Beddington, 1996). Expression later continues in the prospective forebrain and is then restricted to Rathke's pouch, the primordium of the anterior pituitary. Mice homozygous for a null mutation in the Hesxl locus display variable defects in the anterior CNS such as micro- or anophthalmia, and agenesis of midline forebrain derivatives, including the corpus callosum and septum pellucidum. They also exhibit pituitary dysplasia. The phenotype of the Hesxl null mice is similar to human SOD, which consists of congenital panhypopituitarism, optic nerve hypoplasia and/or abnormalities of midline brain structures. A familial form of SOD has recently been described in association with a homozygous mutation in the HESXI locus (Dattani et al., 1998).

Two observations suggest that Hesx1 functions as a transcriptional repressor in vivo. First, Hesx 1 interacts with the co-repressor NcoR1 and can repress the $t k$ promoter through an NcoR1-dependent mechanism (Xu et al., 1998). Second, Hesx 1 also contains an amino acid sequence known as the engrailed homology domain 1 (eh-1) (Smith and Jaynes, 1996). Eh-1 is characterised by a conserved seven amino acid sequence, which is present in a large number of homeodomain proteins (Smith and Jaynes, 1996). In Engrailed, eh-1 is required for both repression in vivo in Drosophila (Smith and Jaynes, 1996) and for repression by Engrailed from integrated reporters in cell culture (Tolkunova et al., 1998).

While mechanisms of transcriptional repression are less well understood than those of activation, several themes have become apparent. Like activators, repressors have modular domains that can function independently of DNA binding to repress transcription. Repressors are believed to act by one of three potential modes: competition with activators for the same binding sites ("passive repression"), a direct inhibitory effect on the transcriptional machinery ("direct repression") or by interacting with a DNA-bound activator to abrogate its activity ("quenching") [reviewed by Hanna-Rose and Hansen, and Levine and Manley (Hanna-Rose and Hansen, 1996; Levine and Manley, 1989)].

We have investigated the molecular basis for a variety of clinical phenotypes that arise as a consequence of mutations in HESXI. As we have worked with both the mouse and human proteins, we will refer to them according to the species-specific nomenclature, Hesx1 (mouse) and HESX1 (human) (Hesx1 will be used for all generalisations). We have screened a large number of patients with pituitary defects and here describe an association between HESXI mutations and the magnetic resonance imaging (MRI) scan findings of an undescended or ectopic posterior pituitary gland. In contrast to the classical SOD phenotype observed with the autosomal recessive HESXI (R160C) mutation we show milder phenotypes in association with the heterozygous HESXI (S170L) mutation. At a molecular level we show that Hesx 1 can bind with high affinity to either dimer or monomer homeodomain DNA sites and that it acts as a transcriptional repressor in transient transfection experiments. Mutations linked to pituitary phenotypes affect DNA binding and not transcriptional repression. However, HESX1(R160C) has a dominant negative activity both in vitro and in vivo and this dominant negative activity requires the repression domain that we have mapped to 36 amino acids containing eh-1 outside of the homeodomain. We also show that the repression domain in Hesx 1 can suppress the activity of a homeodomain based activator of the Prd class. The involvement of the Hesx1 repression domain in mediating functional interactions with partner proteins suggests a possible mechanism whereby mutations in other domains of Hesx 1 may lead to dominant pituitary phenotypes.

\section{MATERIALS AND METHODS}

\section{Plasmid construction}

Gal4-Hesx 1 fusion proteins were constructed identically to the previously described Gal4-Hex fusions (Brickman et al., 2000). The sequence upstream of the Hesxl ATG was modified by polymerase chain reaction (PCR) to ensure the presence of an optimal Kozak sequence flanked by an EcoRI site (5'-GCGAATTCACCATGGTGTCTCCCAGCCTTC). The stop codon was mutated and flanked by a BamHI site (5'-CGCGGGATCCGGGAGCCCTTTCTTCTGG). A series of GAL4- $\lambda$ VP vectors constructed in pBGX-1 (Emami and Carey, 1992) were used to construct Hesx $1-\lambda$ VP2 and $\lambda$ VP4 fusions using the same PCR product. pJBME108 expresses the full length GAL4-Hesx1 fusion while pJBME117/119 expresses GAL4-Hesx1$\lambda$ VP2/ $\lambda$ VP4. All deletions were generated by a PCR based strategy using an analogous set of oligonucleotides to those used to construct pJBME108. The GAL4-Gsc constructs were made by amplifying the relevant fragments of Xenopus Gsc. Reporter constructs employing reiterated 17-mers upstream of the SV40 and E4 promoters were made as previously described (Brickman et al., 2000). The G5E4 reporter was a gift from Dr S Harrison. (P3) 6 E4 and CDNA3-Bix1 were gifts from Dr M. Tada.

\section{Cell culture and transfections}

Feeder-independent ES cells were maintained in gelatinised flasks in Dulbecco's modified Eagle's medium (DMEM) supplemented with $20 \%$ fetal calf serum and leukaemia inhibiting factor (Smith et al., 1988). ES cell lines were E14.2 (Fisher et al., 1989) and CGR8 (Mountford et al., 1994). Transient transfections were performed as described previously (Brickman et al., 2000). COS-7 cells were cultured in DMEM containing sodium pyruvate supplemented with $10 \%$ fetal calf serum. Western blots on transfected COS cells were performed by transfecting $1.2 \mu \mathrm{g}$ of the indicated expression vector into a $1.0 \mathrm{~cm}$ dish by lipofection using Lipofectamine (Gibco BRL) according to the instructions of the manufacturer. Extracts were made in RIPA with gentle agitation at $4^{\circ} \mathrm{C}$ for 30 minutes. Lysates were clarified and diluted with $2 \times$ Laemmli sample buffer. Blots were probed with $\alpha$-VP16 antibody (Santa Cruz) at a concentration of 
$200 \mathrm{ng} / \mathrm{ml}$ and an $\alpha$-mouse horseradish peroxidase antibody (Sigma) at a concentration of $100 \mathrm{ng} / \mathrm{ml}$. They were visualised by chemiluminescence using an ECL kit (Amersham) according to the instructions of the manufacturer.

\section{Purification of recombinant proteins}

All HESX1 proteins were expressed and purified as previously described using derivatives of the plasmid pJBE21, which contains ten histidine residues upstream of an amino-terminal poly-linker (Dattani et al., 1998). Briefly, insoluble material from lysates of Escherichia coli strain BL21/(DE3) was solubilised in $20 \mathrm{mM}$ Tris $\mathrm{pH}$ 8.0, $100 \mathrm{mM} \mathrm{KCl}, 20 \%$ (w/v) glycerol, $6 \mathrm{M}$ urea, $1 \mathrm{mM}$ phenylmethylsulfonyl fluoride and $1 \mathrm{mM}$ imidazole and fractionated by nickel $\left(\mathrm{Ni}^{2+}\right)$ affinity chromatography. HESX1-containing fractions were eluted in a stepwise manner using increasing concentrations of imidazole. The proteins were then renatured by dialysis against $50 \mathrm{mM}$ Tris $\mathrm{pH} 8.0,600 \mathrm{mM} \mathrm{NaCl}, 10 \mathrm{mM} \mathrm{MgCl}$, $20 \%$ (v/v) glycerol, $0.1 \%$ Nonidet P40, $10 \mathrm{mM}$ dithiothreitol and 1 $\mathrm{mM}$ phenylmethylsulfonylfluoride containing decreasing amounts of urea. Electrophoretic mobility shift assays (EMSA) were performed as previously described (Brickman et al., 1999). The oligonucleotides used in the EMSA assays were 5'AGCTTGAGTCTAATTGAATTACTGTAC3' for the P3 site and 5'TCGAGCAATTAAATTCCCAGGATTATC3' and 5'GATCATGATAATCCTGGGAATTTAAGCA3' for the monomeric site in the Gsc promoter. Anti-His antibody was pre-incubated with gel shift reactions as in Fig. $2 \mathrm{C}$ at a concentration of $12.0 \mathrm{ng} / \mu \mathrm{l}$.

\section{Determination of equilibrium constants}

Equilibrium constants were calculated for the binding of the various recombinant forms of the protein to target DNA sequences using standard methods. Briefly, single-stranded DNA was synthesised and purified using a Phenyl Sepharose FPLC column (PharmaciaBiotech). Following initial purification the hyperchromicity of each single strand was determined using UV spectrophotometric methods and phospho-triesterase degradation. Following accurate determination of DNA concentration, complementary strands were annealed. Duplex DNA was again purified using a Phenyl Sepharose column, and concentrations determined as described above. Doublestranded oligonucleotides were labelled by T4 kinase with $\left[\gamma_{-}{ }^{32} \mathrm{P}\right]$ ATP. Excess unincorporated label was removed using G25 spin columns (Pharmacia-Biotech). For a typical binding reaction, 0.1-1 ng of DNA was incubated with various concentrations of recombinant protein, and the reaction mixture loaded onto a pre-electrophoresed acrylamide gel (30 minutes at $90 \mathrm{~V}$ in $1 \times \mathrm{TAE}$ ). Once loaded, the gels were run for a further 40-50 minutes at a constant current (110 mA). Once dried, gels were visualised by autoradiography, and the level of bound and unbound species was determined using phospho-imaging techniques.

\section{Patient recruitment and mutational screening}

A total of 461 patients (163 with classical septo-optic dysplasia, 223 with variable pituitary hormone deficiencies, 9 with optic nerve hypoplasia, 3 with midline neuroradiological abnormalities and 63 with a variety of midline disorders such as holoprosencephaly) were recruited from Great Ormond Street Hospital for Sick Children (GOSH), University College London Hospitals (UCLH) and a variety of other sources. The majority of cases were sporadic apart from the two pedigrees described below and eight other families with variable degrees of SOD and Combined Pituitary Hormone Deficiency (CPHD). Ethical Committee approval for the study was obtained at both GOSH and UCLH. Mutation screening was performed using PCR followed by single-stranded conformational polymorphism (SSCP) as described previously (Dattani et al., 1999; Thomas et al., 2001). Samples showing any band shifts on SSCP analysis were then sequenced. We originally described a homozygous mis-sense mutation C478T (R160C substitution) in two siblings with SOD from a highly consanguineous pedigree (Dattani et al., 1999). More recently, we have described three non-conservative mis-sense heterozygous mutations, namely $\mathrm{C} 509 \mathrm{~T}$ in pedigree 2 (S170L substitution), A541G (T181A substitution) and G18C (Q6H) (Thomas et al., 2001). The C509T and A541G mutations were not found in 140 control chromosomes, and the G18C mutation was not observed in 100 control chromosomes. The inheritance pattern was autosomal dominant with variable penetrance. Additionally, we have documented a heterozygous A374G (N125S) change in 5 children of Afro-Caribbean descent, all of whom have variable SOD phenotypes. We have identified this as a probable polymorphism in the AfroCaribbean population (see below).

\section{RESULTS}

\section{Patient phenotypes \\ R160C}

The phenotype of two children with a homozygous R160C substitution, born to a highly consanguineous pedigree, with panhypopituitarism, absence of the septum pellucidum and agenesis of the corpus callosum, has previously been described (Wales and Quarrell, 1996). More recently, both children have had magnetic resonance imaging performed and representative views are shown in Fig. 1B and 1C (Fig. 1). Interestingly, the two affected siblings had an ectopic/undescended posterior pituitary associated with a hypoplastic anterior lobe in addition to abnormalities of the corpus callosum and septum pellucidum. The scans revealed a degree of optic nerve hypoplasia with small optic chiasma that had no obvious clinical impact. Surprisingly the appearance of the corpus callosum and the size of the pituitary fossa differed in the two siblings. Sibling 1 has partial agenesis of the corpus callosum with a shallow pituitary fossa, whereas the MRI scan performed on sibling 2 shows hypogenesis of the corpus callosum with a well-developed sella turcica.

\section{S170L}

This heterozygous substitution was recently described in two siblings with isolated GH deficiency as determined clinically and by the concentrations of insulin-like growth factor 1 (IGF1) and IGF binding protein 3 (IGFBP3) (Thomas et al., 2001). The older sibling (sibling 1), who also had mild cranio-facial dysmorphism and optic nerve dysplasia, displayed an evolving growth hormone deficiency (GHD), with a reduction in the peak GH response to glucagon stimulation from $14.5(5.6 \mu \mathrm{g} / \mathrm{l})$ to $6.5(2.5 \mu \mathrm{g} / \mathrm{l}) \mathrm{mU} / \mathrm{l}$ over a period of 3 years. In contrast, his brother (sibling 2) had clinical evidence of severe $\mathrm{GH}$ deficiency with undetectable concentrations of IGF-1 and IGFBP3, but with what would be considered to be a normal $\mathrm{GH}$ response to glucagon stimulation $(43.9 \mathrm{mU} / \mathrm{l} ; 16.7 \mu \mathrm{g} / \mathrm{l})$ at the age of 14 months. Treatment with recombinant human growth hormone $(\mathrm{hGH})$ led to a dramatic increase in the growth rate. Since the description of these phenotypes, sibling 2 has been re-tested at the age of 5 years, after discontinuing his $\mathrm{GH}$ treatment over a 6-week period. The peak $\mathrm{GH}$ on re-testing was $20.4 \mathrm{mU} / \mathrm{l}(7.8 \mu \mathrm{g} / \mathrm{l})$ using the same $\mathrm{GH}$ radioimmunoassay as the first test. This borderline response reflected a considerable reduction in $\mathrm{GH}$ secretion as compared with the original test. The thyroid-stimulating hormone (TSH) response to thyrotrophin-releasing hormone (TRH) was normal (peak 15.7 $\mathrm{mU} / \mathrm{l}$ ) as was the prolactin response (peak $660 \mathrm{mU} / \mathrm{l}$ ). The 


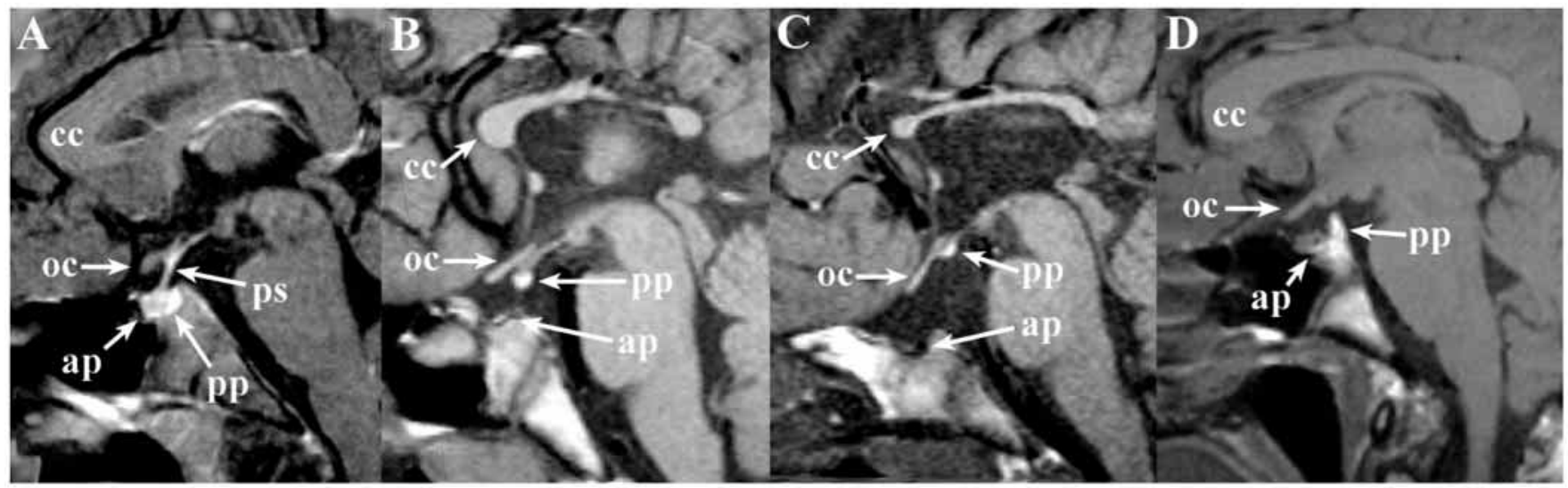

Fig. 1. (A) Sagittal MRI scan of the head of a normal child showing the corpus callosum (cc), the optic chiasm (oc), the anterior pituitary (ap), the pituitary stalk (ps) and posterior pituitary (pp) in the normal sella turcica. Note the well-formed corpus callosum and the optic chiasm and the posterior pituitary which appears as a bright fossa within the sella turcica. (B) Sagittal MRI scan of sibling 1 with a homozygous R160C mutation in HESX1. Note that the splenium of the corpus callosum is more hypoplastic than the rest of the structure and that the sella turcica is shallow as compared with the MRI scan of sibling 2 (C). The posterior pituitary (pp) appears to be partially descended. (C) Sagittal MRI scan of sibling 2 with a homozygous R160C mutation in HESX1. The corpus callosum (cc) is severely hypoplastic, as is the optic chiasm (oc) and the anterior pituitary (ap) located in a well-formed but empty sella turcica. Note the ectopic posterior pituitary (pp) and the lack of a visible pituitary stalk. (D) Sagittal MRI of a patient with S170L mutation in HESX1. Note the atrophic posterior pituitary (pp) that has not descended completely into the fossa and an anterior pituitary (ap) gland that is hypoplastic and does not enhance well. The pituitary stalk is thin, but the optic chiasm (oc) is normal as is the corpus callosum (cc).

pituitary glands in these two children were normal on MRI scanning.

A third patient with the S170L substitution has recently been identified. The patient presented at the age of 6 years with short stature, having grown with a sub-optimal height velocity since the age of 2 years. His birth weight was $3.5 \mathrm{~kg}$ and the delivery was unremarkable. On presentation, the patient had a height well below the 0.4 th height centile $(99.7 \mathrm{~cm}$ at 6.4 years). His vision was reported as being normal and fundoscopy revealed no abnormal findings. An insulin tolerance test combined with a TRH test was performed to assess his pituitary function, and revealed a peak $\mathrm{GH}$ response to hypoglycaemia of $1.1 \mathrm{mU} / \mathrm{l}$ $(0.4 \mathrm{ng} / \mathrm{ml})$, confirming a diagnosis of severe GH deficiency. His cortisol secretion was normal (peak cortisol $772 \mathrm{nmol} / \mathrm{l}$ ) as were his TSH (peak $8.2 \mathrm{mU} / \mathrm{l}$ ) and prolactin (peak $799 \mathrm{mU} / \mathrm{l}$ ) responses to TRH. He was treated with recombinant hGH until the age of 15 years, by which time he had achieved a height of $169.7 \mathrm{~cm}$, which placed him between the $9^{\text {th }}$ and $25^{\text {th }}$ centiles (mid-parental centile $25^{\text {th }}$ ). He progressed through puberty normally. His hypothalamo-pituitary axis was re-tested following cessation of the $\mathrm{GH}$ treatment and he achieved a peak GH response of $0.9 \mathrm{mU} / \mathrm{l}(0.36 \mathrm{ng} / \mathrm{ml})$ on re-testing, with normal thyroid function and cortisol concentrations. Magnetic resonance imaging of his brain and pituitary gland revealed an atrophic posterior lobe of the pituitary gland that had not descended into the pituitary fossa. The pituitary stalk was very thin with a poorly enhancing anterior pituitary (Fig. 1D). No other midline structural defects were identified. In spite of the abnormal appearance of the posterior pituitary gland, this patient did not manifest diabetes insipidus.

The heterozygous S170L mutation was clearly associated with highly variable phenotypes in terms of the presence of optic nerve hypoplasia and MRI scan appearances. However, it is noteworthy that all of the affected individuals demonstrated a defect in GH secretion with no other pituitary hormone deficit, suggesting that somatotropes may be particularly vulnerable to perturbations in HESX1.

\section{N125S}

Five of our 461 patients were heterozygous for the N125S substitution in HESXI. All of these patients were of an AfroCaribbean background. This substitution is probably a frequent polymorphic variant within this particular ethnic group. Screening an unaffected Afro-Caribbean population for this polymorphism revealed 5 homozygotes for the wild-type allele, 17 homozygotes for the N125S substitution and 20 heterozygotes for the substitution. However, this mutation may not be entirely silent since the substitution of a serine residue by proline at the analogous position 18 in the homeodomain of Prop1 has previously been implicated in the phenotype of the Ames dwarf mouse (Sornson et al., 1996).

\section{DNA-binding properties of HesX1/HESX1 and HESX1 mutants}

We have previously shown that the R160C substitution in HESX1 resulted in a loss of DNA binding, even at micromolar concentrations, as compared with the wild-type protein which had a high DNA-binding affinity for the consensus P3 DNA sequence (Wilson et al., 1993), a synthetic palindrome shown to bind prd homeodomain proteins (Table 1). To further

\section{Table 1. Dissociation constants for DNA binding to the P3 palindrome and monomeric GBS sequences}

\begin{tabular}{lcc}
\hline Protein & $K_{\mathrm{d}}$ at P3 $(\mathrm{nM})$ & $K_{\mathrm{d}}$ at $\mathrm{GBS}(\mathrm{nM})$ \\
\hline HESX1 & 31 & 180 \\
HESX1 (N125S) & 20 & 78 \\
HESX1 (S170L) & 150 & 1000
\end{tabular}

The sequences of these sites and sample EMSA experiments can be found in Fig. 2. 

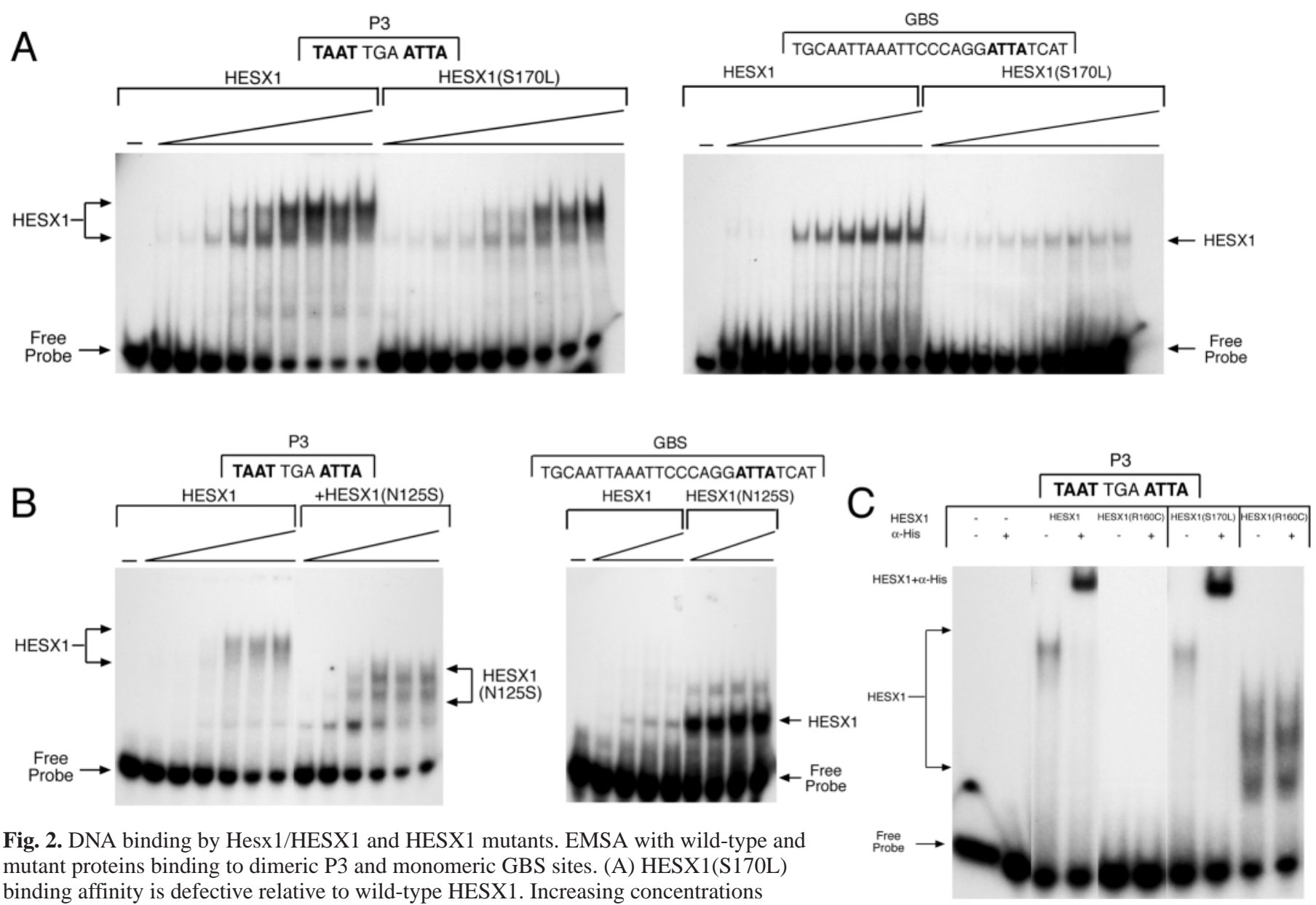

Fig. 2. DNA binding by Hesx1/HESX1 and HESX1 mutants. EMSA with wild-type and mutant proteins binding to dimeric P3 and monomeric GBS sites. (A) HESX1(S170L) binding affinity is defective relative to wild-type HESX1. Increasing concentrations (0.9-240 nM) of purified recombinant WT HESX1 or HESX1(S170L) were added to the labelled binding sites indicated. (B) HESX1(N125S) binds DNA with at least wild-type affinity. Increasing concentrations (0.78-25 nM) of purified recombinant wt HESX1 or HESX1 (N125S) were added to the labelled P3 and monomeric GBS sites respectively. (C) Wild-type HESX1 and HESX1(S170L), but not HESX1(R160C) and HESX1(N125S), could form ternary complexes with an antibody to the aminoterminal His tag. All proteins were added at concentrations of $25 \mathrm{nM}$.

examine the molecular consequences of point mutations associated with both heritable and sporadic forms of SOD, we over-expressed and purified from bacteria wild-type HESX1, HESX1(S170L), HESX1(R160C) and HESX1(N125S). Fig. 2 shows the binding of the HESX1(S170L) and HESX1(N125S) proteins to two classes of homeodomain site, the dimeric P3 site and a naturally occurring site, known as GBS, from the Brachyury promoter, which is thought to bind paired class homeodomains as monomers (Latinkic and Smith, 1999). Table 1 shows the dissociation constants for the binding of the various proteins to these two sites. Fig. $2 \mathrm{C}$ shows a ternary complex formed by HESX1 and an antibody to the aminoterminal histidine (His) tag. The presence of this antibody appears to stabilize the DNA-protein complex formed by both the wild-type HESX1 and HESX1(S170L).

HESX1(R160C) did not bind DNA even in the presence of the $\alpha$-His antibody, confirming our previous observation (Dattani et al., 1998). Moreover, HESX1(N125S) did not appear to interact with the $\alpha$-His antibody under native conditions. This is not a result of the removal of the His tag since a western blot using the same antibody confirmed the presence of the His-tag in a protein preparation that is $80 \%$ homogeneous (data not shown). Interestingly, HESX1(N125S) migrated faster in EMSA than the wild-type protein (Fig. 2B), suggesting that the substitution of asparagine by serine resulted in a difference in either the conformation or the charge of the protein. HESX1(N125S) also appeared to bind DNA with a slightly higher affinity than wild-type HESX1 (Fig. 2B; Table 1).

\section{HESX1/HesX1 is a transcriptional repressor and contains a $\mathbf{3 6}$ amino acid repression domain}

In order to further characterise mutations in HESXI associated with SOD we extended our functional studies from DNA binding in vitro to transcriptional regulation and DNA binding in vivo as assayed by transient transfection assays. Fig. 3A shows that Hesx1 is a transcriptional repressor when fused to the DNA-binding domain of GAL4. DNA encoding GAL4Hesx1 was co-transfected into ES cells together with a reporter containing GAL4 DNA-binding sites upstream of the SV40 promoter. Identical results were obtained in COS cells (data not shown). Fig. 3A shows that the repression activity mapped to 36 amino acids (aas) at the amino terminus of Hesx 1 in a region that is highly conserved across species boundaries. Deletion or removal of this region from Hesx 1 resulted in a dramatic reduction in repression by GAL4-Hesx1, but had no 
Fig. 3. Hesx 1 is a transcriptional repressor with a 36 amino acid repression domain. Increasing concentrations of plasmids expressing the depicted GAL4Hesx 1 fusions were cotransfected with a reporter containing five GAL4 sites upstream of the SV40 promoter (A-C) or E4 promoter (D) driving luciferase into ES cells. Arrows indicate increasing concentrations of transfected GAL4 fusion. In A, $\mathrm{B}$ and C, 200 and $500 \mathrm{ng}$ of expression vector were used respectively. In D increasing concentrations of GAL4Hesx 1(1-49) from $50 \mathrm{ng}$ to 500 ng were co-transfected with the E4 promoter fragment $(50,100$, $250,400,500)$.

A
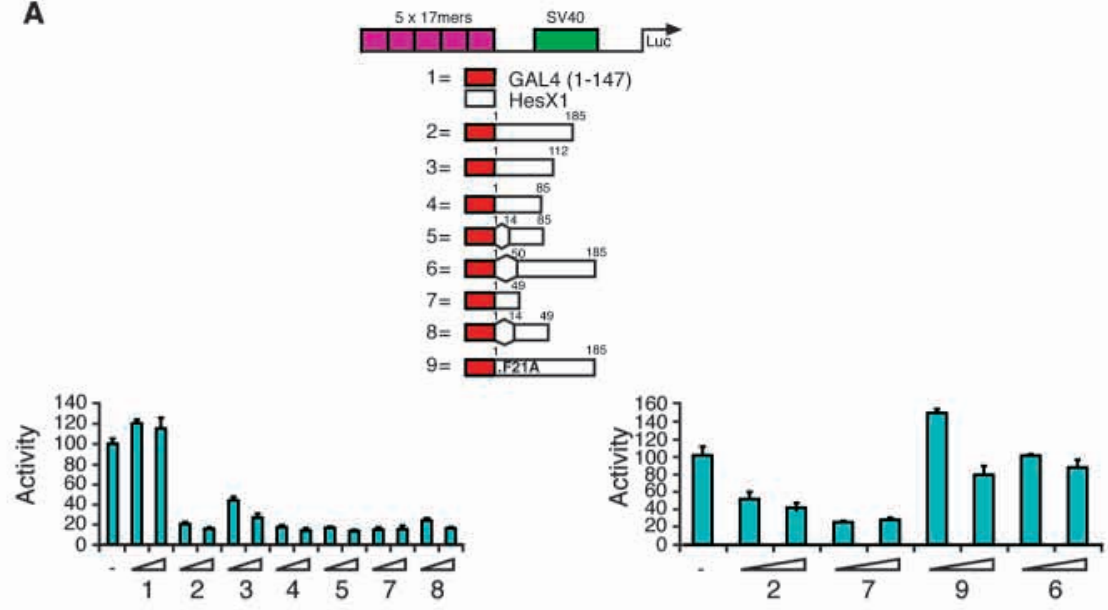

B
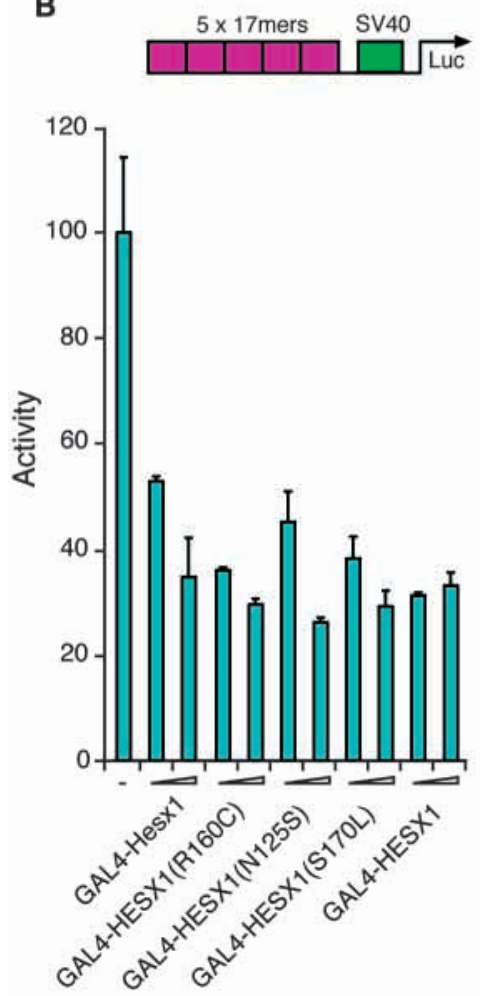

C
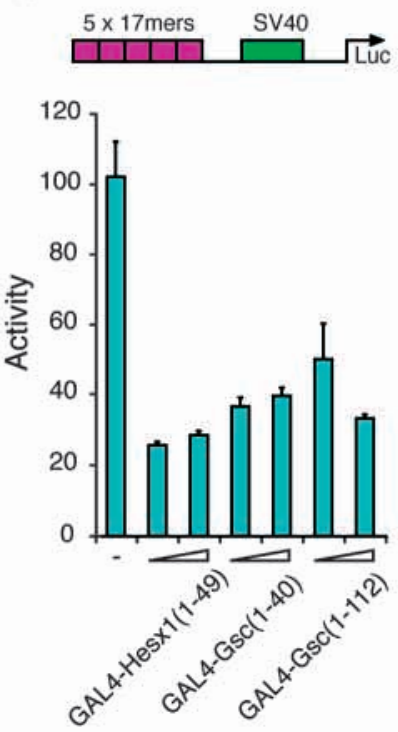

D
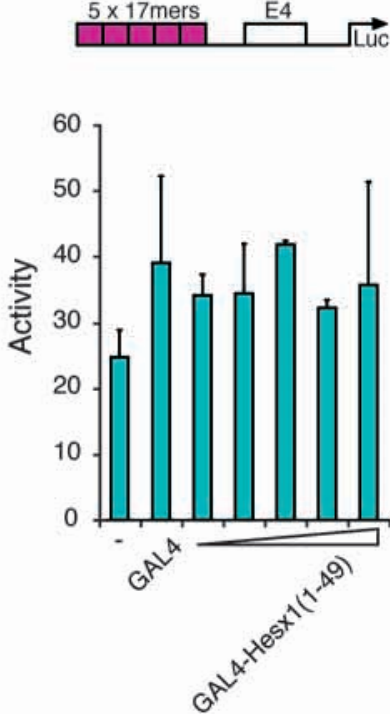

noticeable effect on the levels of Hesx1 expressed in transfected COS cells as determined by western blot analysis (Fig. 4). This region contains a stretch of seven amino acids, FSIESIL, previously implicated in transcriptional repression by Engrailed and Goosecoid, the eh-1 or Engrailed homology domain. A point mutation in eh-1 resulting in the substitution of the conserved Phe by Glu significantly compromises its activity (Smith and Jaynes, 1996; Tolkunova et al., 1998). Fig. 3A shows that mutation of the analogous position in Hesx1, Hesx1F21A, resulted in a loss of repression activity by GAL4Hesx 1 .

Consistent with the localisation of repression activity to this conserved amino terminal domain, we find that GAL4-HESX1 (human as opposed to mouse), GAL4-HESX1(R160C), GAL4HESX1(N125S) and GAL4-HESX1(S170L) were equally able to repress transcription stimulated by the SV40 promoter (Fig.
3B). Moreover, another eh-1 containing protein, Gsc also contains a 40 aa peptide capable of repressing SV40 (Fig. 3C).

Fig. 3D shows that a completely different result was obtained when these GAL4 fusion proteins were assayed from the minimal Adenovirus E4 promoter element. When a minimal 49 amino acid Hesx 1 peptide fused to GAL4 was assayed off this promoter, it had no effect on transcription, wherease the same fragment repressed SV40 transcription 6fold. Repression by HESX1 therefore appears to be a promoterspecific phenomenon, and presumably involves interaction with partner proteins since the SV40 promoters contains several consensus homeodomain sites while the E4 promoter does not.

We therefore tested the ability of Hesx 1 to repress transcription from the minimal Adenovirus E4 promoter containing an upstream P3 site when it was activated by a 


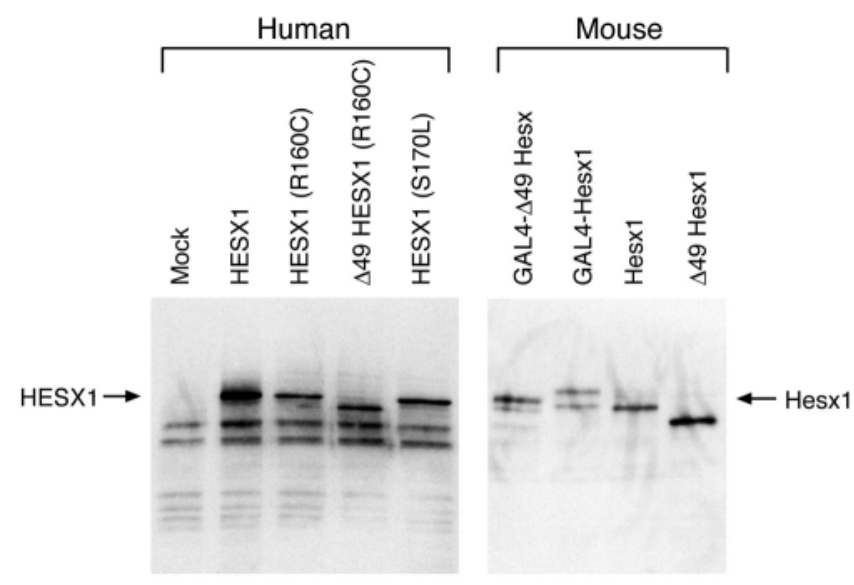

Fig. 4. Hesx 1 fusion proteins are all expressed in COS cells. Western blot analysis using Hesx $1-\lambda$ VP16 fusions with a monoclonal antibody directed at the minimal VP16 activation region. Both mouse and human proteins are expressed at equivalent levels and both mutations in the homeodomain and truncation of the amino-terminal repression domain do not appear to affect these levels.

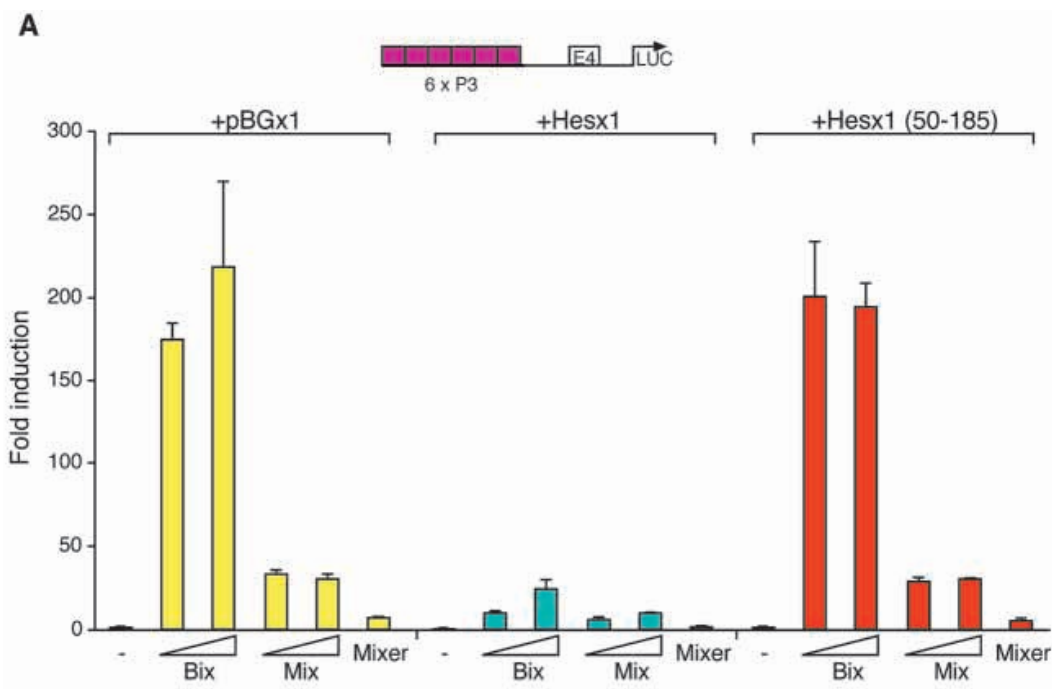

B
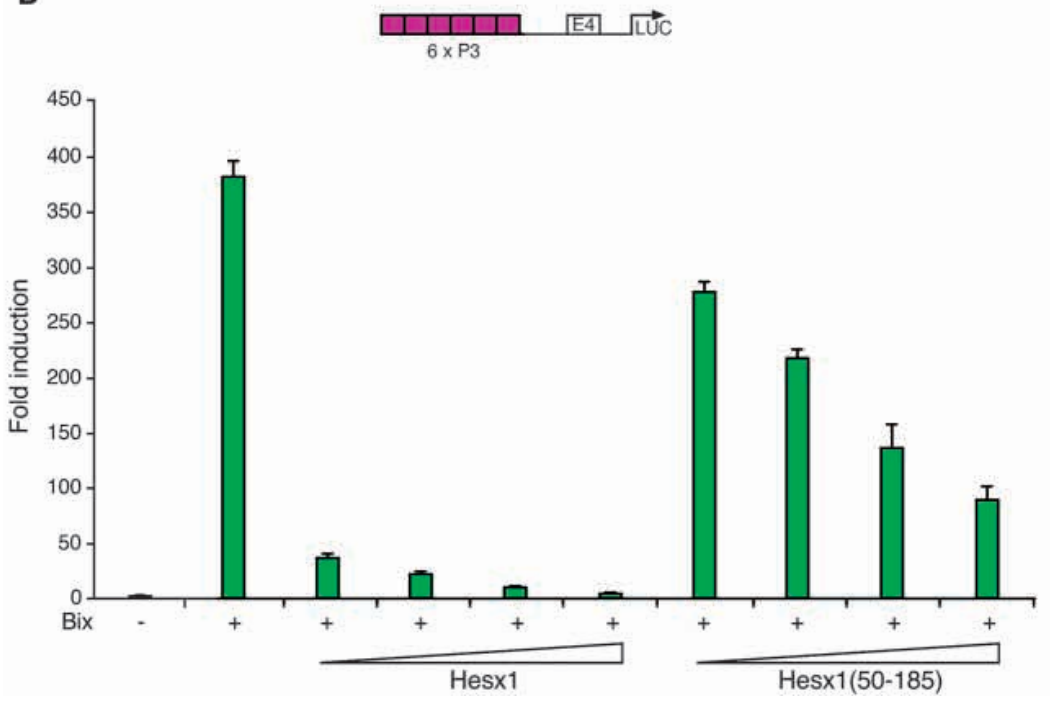

homeodomain-containing activator. Co-transfection of DNA encoding full-length Hesx1, together with expression vectors for paired class activators of the Mix family (Germain et al., 2000), Bix (Tada et al., 1998), Mix-1 (Mead et al., 1996) and Mixer (Henry and Melton, 1998) led to a dramatic repression of these transcriptional activators (Fig. 5A). Hesx 1 was able to repress transcription activated by Bix 91-fold. However, when DNA encoding Bix was co-transfected with a plasmid expressing a Hesx 1 deletion derivative lacking the repression domain, Hesx1(50-185), Bix-mediated activation was repressed by only up to 4.2 -fold, even when DNA encoding Hesx1(50-185) was present in equimolar amounts to that encoding the Bix activator (Fig. 5B). When DNA expressing full-length Hesx 1 was present at 10-fold lower levels than those of the vector expressing the Bix activator, activation by Bix was still significantly repressed (greater than 10-fold) whereas DNA expressing Hesx1(50-185) had no significant effect on Bix activity at these levels (Fig. 5B). Since the quantity of Hesx 1 required for these effects appears well below that required to saturate for DNA binding, we refer to this as cooperative repression.

One simple interpretation of these results is that Hesx1(50-185) binds DNA less well than the fulllength protein and that the loss of repression by Hesx1(50-185) is the result of reduced DNAbinding affinity in vivo. To control for this possibility, we have employed a tripartite fusion protein in which Hesx 1 was fused to both the DNA-binding domain of GAL4 and the transcriptional activation domain of VP16. Hesx1, Hesx 1(50-185) and HESX1 mutant proteins were fused to a modular activation domain derived from the Herpes Simplex Virus transactivator, VP16 (Emami and Carey, 1992). This fusion contains

Fig. 5. Hesx 1 represses transcription induced by paired class activator proteins. (A) Hesx 1 but not Hesx1(50185) can repress transcription stimulated by Bix, Mix1, and Mixer. Expression vectors for these paired class activators were co-transfected along with the indicated reporter, $(\mathrm{P} 3)_{6} \mathrm{E} 4$, which contains six dimeric paired class binding sites upstream of the minimal E4 promoter and expression vectors for either GAL4(1147), GAL4(1-147)-Hesx1 or GAL4(1-147)-Hesx1(50$185)$. Increasing concentrations of expression vectors (25 and $100 \mathrm{ng}$ ) for Bix and Mix and $100 \mathrm{ng}$ for Mixer were co-transfected with $25 \mathrm{ng}$ of the indicated Hesx 1 derivative. (B) Cooperative repression by Hesx 1 but not Hesx 1(50-185). A Bix expression vector was cotransfected with the $(\mathrm{P} 3)_{6} \mathrm{E} 4$ as in A. Increasing amounts of GAL4-Hesx1 or GAL4-Hesx 1(50-185) were co-transfected with the Bix reporter. Titrations of the Bix expression vector were used to determine the optimal levels of induction of the $(\mathrm{P} 3)_{6} \mathrm{E} 4$ reporter. Optimal levels of induction were found to be between 220- and 380-fold depending on the experiment. The addition of expression vector encoding either full length Hesx 1 or Hesx1(50-185) always produced the same repressed level of transcription (i.e. 20-fold when Bix was co-transfected with $25 \mathrm{ng}$ of vector encoding full length GAL4-Hesx 1 compared to 225-fold when Bix was co-transfected with vector encoding GAL4Hesx1(50-185)). 
A

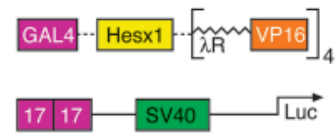

Fig. 6. Defect in repression by Hesx 1(50-185) is not due to a defect in its DNA binding affinity or overall stability of Hesx 1 fusions. (A) Relative activity of GAL4-Hesx1, GAL4-Hesx1(50185), GAL4-Hesx $1-\lambda$ VP4 and GAL4-Hesx 1(50-185)- $\lambda$ VP4 from GAL4 sites. Vectors expressing these fusion proteins were cotransfected with the indicated reporters as in Fig. 3. B) Relative activity of GAL4-Hesx 1- $\lambda$ VP4 and GAL4-Hesx 1(50-185)- $\lambda$ VP4 on $\mathrm{P} 3$ sites. Transfections were performed as in A except the reporter is $(\mathrm{P} 3)_{6} \mathrm{E} 4$.
B
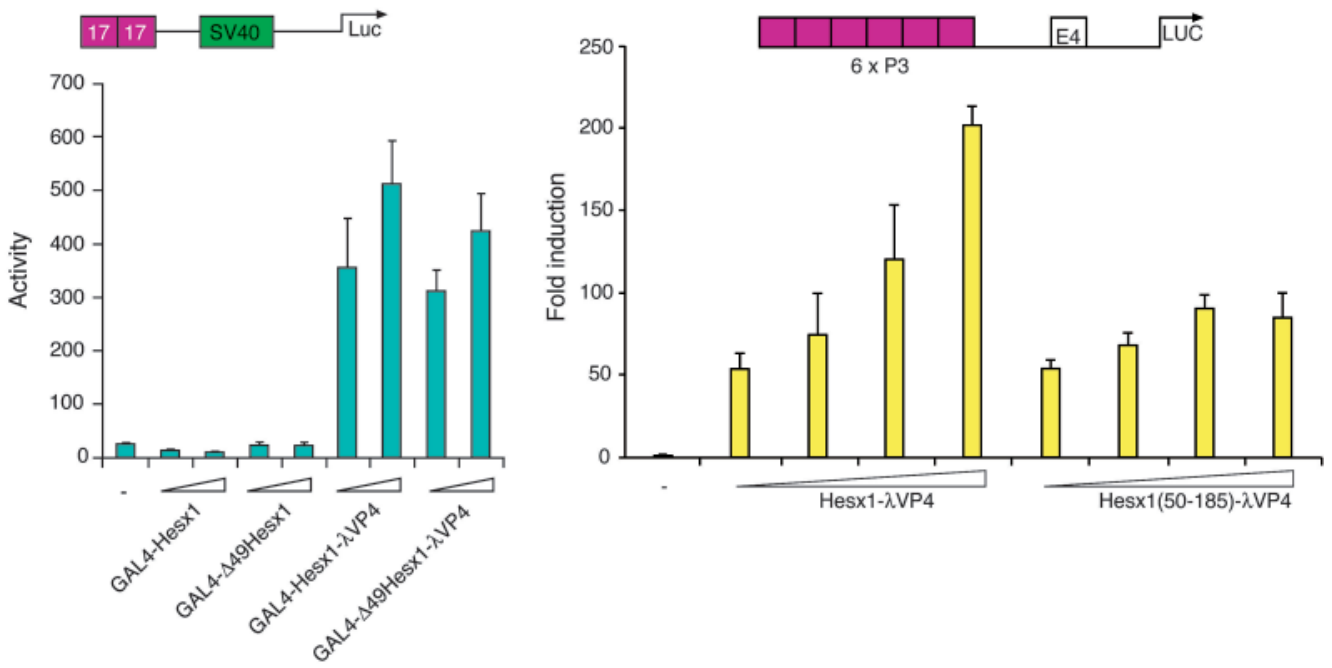

reiteration of a modular activation unit that has been used to convert homeodomain-containing transcriptional repressors to activators without removing their endogenous repression domain (Brickman et al., 2000). The construction of these fusion proteins is illustrated in Fig. 6A. Fig. 6A shows that the tripartite fusion protein GAL4-Hesx1- $\lambda$ VP4 was a potent activator of transcription when bound to GAL4 binding sites positioned upstream of the SV40 promoter. The activity of the tripartite fusion GAL4-Hesx $1-\lambda \mathrm{VP} 4$ was the same as that of GAL4-Hesx1(50-185)- $\lambda$ VP4. This is consistent with the expression level of these proteins as determined by western blots on transfected COS cells (Fig. 4). Moreover, when these tripartite proteins were tested from $\mathrm{P} 3$ site containing reporters (Fig. 6B) similar results were obtained, at least when the tripartite proteins were present at limiting concentrations. Thus when lower levels of either Hesx1 or Hesx1(50-185) expression vectors were transfected alongside the P3 site containing reporter, they activate transcription to similar degrees, suggesting that the removal of the $\mathrm{N}$ terminus in the context of this fusion protein does not impair binding to the P3 DNA element.

\section{Dominant negative activity of HESX1(R160C) requires the presence of the Hesx1 repression domain}

Our previous data have shown that HESX1(R160C) cannot bind DNA in its own right. However, we tested its binding in the context of a heterodimer, fully anticipating that it would not affect the ability of the wild-type protein to bind target DNA since all of the nine human heterozygotes for the R160C substitution did not manifest a phenotype (Dattani et al., 1998). Fig. 7A shows that addition of stochiometric quantities of HESX1(R160C) to a DNA binding experiment with wild-type HESX1 led to a significant reduction in DNA-binding by the wild-type HESX1 protein. Heat-denatured HESX1(R160C) did not have this effect (Fig. 7A) and, when wild-type HESX1 was combined with the wild-type mouse protein (Hesx1), it did not affect Hesx1 binding. However, HESX1(R160C) had the same dominant negative effect on the mouse as it did on the human protein (data not shown).
The nanomolar concentrations of HESX1 used in these experiments suggested HESX1 and HESX1(R160C) interact with high affinity in solution to form an inactive complex, the simplest form of which would be heterodimers. To test this interaction in another context we employed an in vivo recruitment assay. In this experiment DNA binding by HESX1 was inferred from the activity of HESX1- $\lambda$ VP4 on a reporter gene that contained 6 P3 sites upstream of the minimal Adenovirus E4 promoter in transient transfection. Fig. 7B shows that co-transfection of increasing amounts of DNA expressing HESX1- $\lambda$ VP4 alongside this reporter produced potent, dose-dependent activation of the reporter. Inclusion of DNA encoding HESX1(R160C)- $\lambda$ VP4 in this transfection led to a dramatic reduction in the transcriptional activity of the wild-type fusion protein (Fig. 7B), similar to the in vitro data shown in Fig. 7A. Excess HESX1(R160C)- $\lambda$ VP4 completely blocks the activity of HESX1- $\lambda$ VP4, but when HESX1(R160C)- $\lambda$ VP4 is present at stochiometric or substochiometric levels (last two points in the curve), HESX1$\lambda \mathrm{VP} 4$ regains partial activity on the $\mathrm{P} 3$ site reporter suggesting a possible 1:1 relationship between the wild-type and mutant proteins. Fig. 7B also shows that the eh-1-containing aminoterminal repression domain is required for the inhibitory effect of HESX1(R160C) as co-transfection of DNA expressing HESX1(50-185)(R160C)- $\lambda$ VP4 has no effect on the activity of HESX1- $\lambda$ VP4.

\section{DISCUSSION}

We have shown that Hesx 1 is a high affinity DNA-binding protein that behaves as a promoter-specific repressor. The repression domain maps to the $\mathrm{N}$ terminus and contains a sequence known as eh-1 that was initially identified in Engrailed and is necessary for repression. One mechanism by which eh-1 may function is via the recruitment of the Drosophila co-repressor, Groucho (Jimenez et al., 1997). In fact, a nine amino acid sequence including the eh-1 sequence from Gsc can interact with Groucho in vitro (Jimenez et al., 1999). In the case of Drosophila Gsc, eh-1 has also been shown 
A

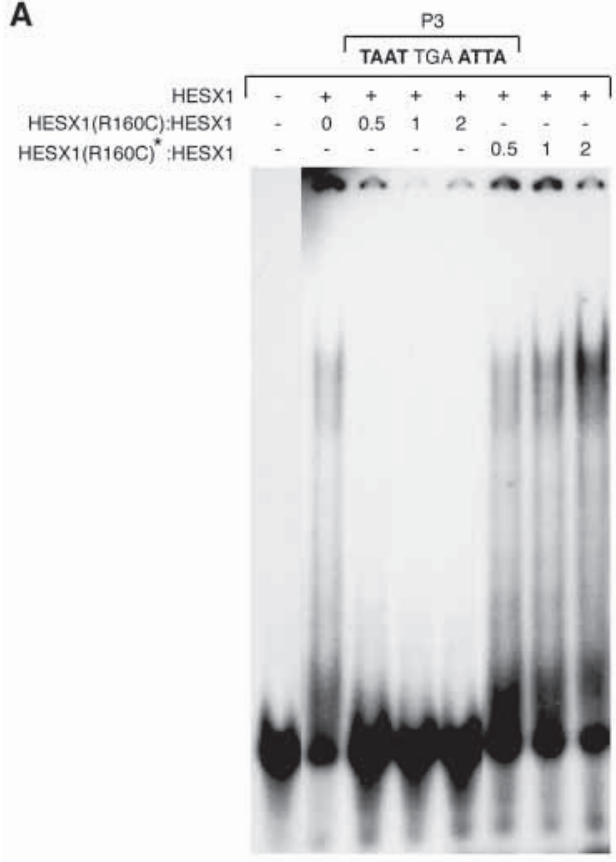

B

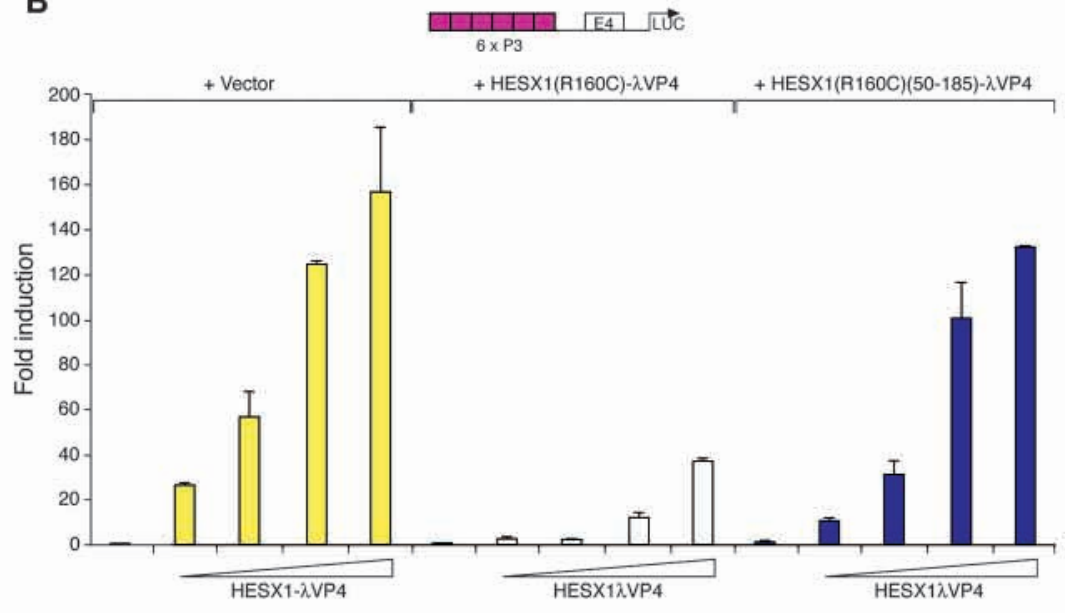

Fig. 7. Dominant negative activity of HESX1(R160C) requires amino terminal repression domain. (A) Dominant negative activity of HESX1(R160C) in vitro. Recombinant HESX1(R160C) (50-200 nM) was mixed together with wild-type HESX1 protein (100 $\mathrm{nM}$ ) and incubated with radiolabeled DNA containing a P3 binding site. The numbers above the lanes indicate the molar ratio of HESX1(R160C) or heat denatured (denoted by *) HESX1(R160C) to wild-type protein. (B) Dominant negative activity of HESX1 in vivo depends on the amino terminal repression domain. Increasing concentrations of wild-type HESX1- $\lambda$ VP4 expression vector (20, 50, 150 and $400 \mathrm{ng}$ ) were co-transfected with the P3 luciferase reporter. Wild-type HESX1- $\lambda$ VP4 expression vector was co-transfected with $400 \mathrm{ng}$ of either HESX1(R160C)- $\lambda$ VP4 or HESX1(R160C)(50-185)- $\lambda$ VP4.

to mediate repression by facilitating the formation of heterodimers with other homeodomain proteins. Eh-1 is required for Gsc-mediated repression of Otd (now known as ocelliless; Oc), but not for direct repression of transcriptional activation induced by the Glucocorticoid receptor (Mailhos et al., 1998).

The eh-1-containing domain from Hesx1 repressed transcription from the SV40 promoter, or transcriptional activation stimulated by prd homeodomain-containing activators, but not from the minimal Adenovirus E4 promoter. Mutations in HESX1 associated with SOD affect DNA binding, rather than transcriptional repression. One of these mutations, HESX1(R160C), has a dominant negative effect on HESX1, both in vivo and in vitro. This activity is dependent on the eh1-containing $\mathrm{N}$-terminal repression domain.

\section{Promoter-specific/cooperative repression by Hesx1}

Hesx1-mediated repression does not affect the minimal Adenovirus E4 promoter, which contains a consensus TATA box and initiator but no additional regulatory sequences (Lin et al., 1988). Hesx 1 is therefore unable to mediate repression through a direct interaction with the basal transcription complex bound at the E4 promoter. However, when Prd class homeodomain-binding sites are placed upstream of the E4 promoter and a prd class homeodomain activator is added, Hesx 1 can now repress transcription stimulated by the homedomain activator. There are two possible mechanisms by which this might occur: direct competition between the two homeodomain proteins for the P3 DNA site, or direct inhibition by Hesx 1 of the activity of the homeodomain-containing activator through a physical interaction. Direct competition would not explain the magnitude of repression (up to 100-fold) observed in these experiments unless there were major differences in DNA binding affinity. However, the activities of Bix and Hesx $1-\lambda$ VP4 over a range of concentrations suggest similar DNA binding affinities for the P3 site. Assuming that these proteins do have similar DNA binding affinities, direct competition could explain the magnitude of repression observed by Hesx1(50-185) (4-fold) when Hesx 1(50-185) and Bix are present at a 1:1 ratio. Hesx 1 can also repress transcription when it is present at 10-fold lower levels than the Mix family activator protein suggesting that formation of a heteromeric complex with the Mix family protein on DNA is cooperative and that repression occurs via an active quenching mechanism.

The ability of Gal4-Hesx 1 fusions to repress the SV40 promoter is probably due to the presence of homeodomain activators. In addition to the multiple Sp1 sites and AT rich sequences immediately adjacent to the transcription start site [reviewed by McKnight and Tjian (McKnight and Tjian, 1986)], the SV40 promoter contains two perfect consensus sites for binding homeodomain proteins of the Caudal-like and Deformed families.

Several recent studies have implicated the eh-1 sequence within engrailed (Jimenez et al., 1997; Tolkunova et al., 1998), UNC-4 (Winnier et al., 1999), and Gsc (Jimenez et al., 1999) in the recruitment of the co-repressor Groucho. General recruitment of a global co-repressor such as Groucho would imply a more direct mechanism for transcriptional repression by eh-1 and suppression of basal transcription. However, the implication of our data is that eh-1 in Hesx 1 mediates an interaction with other homeodomain-containing proteins to form a complex that can serve as a promoter-specific binding surface for Groucho. The interaction between a homeodomain 
or DNA binding motif with a repression domain may be a general feature of co-repressor recruitment. For example, Dorsal, which functions as both an activator and a repressor, interacts with co-factors that modulate both its promoterspecific regulatory activity (Brickman et al., 1999) and its capacity to recruit Groucho (Dubnicoff et al., 1997; Valentine et al., 1998) via its conserved DNA binding motif, the Rel domain.

\section{Repression and dimerisation}

The repression domain of Hesx 1 is required for the dominant negative activity of HESX1(R160C). These findings are consistent with two observations with respect to Gsc eh-1; Gsc eh-1 mediates its physical interaction with the homeodomain of Otd and heteromeric repression by Gsc eh-1 is disrupted by mutations in the Otd homeodomain that interfere with dimerisation (Mailhos et al., 1998). In contrast to the isolated prd homeodomain, thought to be a monomer in solution (Wilson et al., 1993), our experiments with the HESX1(R160C) in vivo and in vitro suggest that full-length Hesx 1 forms dimers in solution, and that this is dependent upon eh-1. The requirement of eh-1 for dimerisation and repression would be consistent with a model in which eh-1 interacts with homeodomain containing proteins to form a complex that can then recruit co-repressors such as Groucho.

This is one of the first reports of binding constants for intact recombinant proteins. We have determined the $K_{\mathrm{d}}$ s for the binding of all proteins to both monomeric and dimeric sites. Our binding studies on the dimeric P3 site show a significant change in the dissociation constant, suggesting that the difference in $K_{\mathrm{d}}$ (6-fold) between the monomeric and dimeric sites was based upon the affinity of a dimer formed in solution for the P3 target sequence.

\section{Implications for clinical phenotypes associated with HESX1 mutations}

Our studies have suggested a rare role for HESX1 in milder pituitary phenotypes. It is noteworthy that all of our patients who have been documented as having mutations in HESXI have impaired $\mathrm{GH}$ secretion with clinical evidence of $\mathrm{GH}$ deficiency. Additionally, HESXI is the only gene to date associated with an ectopic/undescended posterior pituitary gland. Mutations in PIT1, PROP1 and LHX3 are associated with a posterior pituitary in the normal position in the sella turcica (Fofanova et al., 2000; Netchine et al., 2000; Parks et al., 1999). We screened 93 individuals with an ectopic/ undescended posterior pituitary and found HESX1 mutations in only 5 individuals. The descent of the posterior pituitary may therefore be dependent upon a number of developmental genes that are expressed at an early stage of pituitary organogenesis. The association of an ectopic/undescended posterior pituitary with isolated $\mathrm{GH}$ deficiency suggests that somatotrope differentiation/proliferation and consequent GH secretion may be particularly vulnerable to dissociation between the anterior (derived from Rathke's pouch) and posterior (derived from neuroectoderm) lobes.

Based on our in vitro studies, we would predict that, in the absence of allelic exclusion, a patient who is heterozygous for HESX1(R160C) would have much less than $50 \%$ of active HESX1 protein. Based on dominant negative experiments with wild-type HESX1 we would predict that these patients may have as little as $10 \%$ of the normal concentrations of active wild-type HESX1 dimers. The implication of these findings is that there may be sufficient active protein to escape a phenotype in a statistically significant number of patients. These observations may be consistent with the variable penetrance of the Hesxl targeted mutation in mice (Dattani et al., 1998). By analogy, it

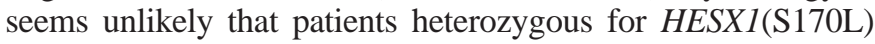
would display a phenotype, if the only consequence of this mutation was to reduce DNA binding of one allele by 5-fold (based on $K_{\mathrm{d} S}$ determined for both dimer and monomer sites). The S170L substitution is located immediately C-terminal to the homeodomain in an RESQLF motif, which is completely conserved in, and unique to, HESX1 homeoproteins. Recent structural studies of Pbx 1 class homeodomains highlight the importance of homeodomain-flanking residues/motifs and may provide insight into the functional role of the RESQLF motif (Piper et al., 1999). Pbx class homeodomains, which bind as heterodimers with Hox class proteins, also contain a conserved stretch of residues $\mathrm{C}$-terminal to the homeodomain. In Pbx1 these residues fold into a fourth $\alpha$-helix that forms an integral part of the homeodomain-binding complex by making specific contacts with homeodomain residues. Replacement of the F298 residue within the $\mathrm{Pbx}$ homeodomain C-terminal tail (F298 is the homologous position to $\mathrm{S} 170$ in Hesx1) results in a reduction in both monomeric and cooperative DNA binding ( $\mathrm{Lu}$ and Kamps, 1996). This analogy suggests that the S170L mutation is positioned such that it alters interactions between Hesx 1 and its partners, suggesting a possible mode for dominant inheritance.

Modulation of the interactions between Hesx 1 and partner proteins involved in normal forebrain and pituitary development may explain the variable penetrance and expressivity of the SOD phenotype (Arslanian et al., 1984). The expression patterns of members of the Mix family suggest that they may be true physiological partners of Hesx 1 and thus candidates for additional mutations associated with the SOD phenotypic spectrum.

We are indebted to Professor Iain Robinson for his support and guidance throughout the course of these studies and during the preparation of this manuscript. We are grateful to Dr John Old (National Haemoglobin Centre, Institute of Molecular Medicine, John Radcliffe Hospital, Oxford) for the supply of control DNA from an Afro-Caribbean population and to collaborating clinicians for supplying DNA samples from suitable patients. We would particularly like to thank Dr Jerry Wales, Senior Lecturer in Paediatric Endocrinology at the Children's Hospital, Sheffield, UK, for his help during the course of these studies. We would like to thank Drs Tristan Rodriquez, Valerie Wilson and Grace Gill for critical comments on this manuscript and Drs Mike Carey, Lee Henry, Masa Tada, Branko Latincik and Steve Harrison for plasmids. This work was supported by the Medical Research Council and MTD is the recipient of an MRC Career Establishment Grant.

\section{REFERENCES}

Arslanian, S. A., Rothfus, W. E., Foley, T. P., Jr and Becker, D. J. (1984). Hormonal, metabolic, and neuroradiologic abnormalities associated with septo-optic dysplasia. Acta Endocrinol. 107, 282-288.

Brickman, J. M., Adam, M. and Ptashne, M. (1999). Interactions between an HMG-1 protein and members of the rel family. Proc. Natl. Acad. Sci. USA 96, 10679-10683.

Brickman, J. M., Jones, C. M., Clements, M., Smith, J. C. and Beddington, 
R. S. P. (2000). Hex is a transcriptional repressor that contributes to anterior identity and suppresses Spemann organiser function. Development 127, 2303-2315.

Dattani, M. T., Martinez-Barbera, J. P., Thomas, P. Q., Brickman, J. M., Gupta, R., Martensson, I. L., Toresson, H., Fox, M., Wales, J. K., Hindmarsh, P. C. et al. (1998). Mutations in the homeobox gene HESX1/Hesx 1 associated with septo-optic dysplasia in human and mouse. Nat. Genet. 19, 125-133.

Dattani, M. T., Martinez-Barbera, J. P., Thomas, P. Q., Brickman, J. M., Gupta, R., Wales, J. K., Hindmarsh, P. C., Beddington, R. S. and Robinson, I. C. (1999). HESX1: a novel gene implicated in a familial form of septo-optic dysplasia. Acta Paediatr. Suppl. 88, 49-54.

Desplan, C., Theis, J. and O'Farrell, P. H. (1988). The sequence specificity of homeodomain-DNA interaction. Cell 54, 1081-1090.

Dubnicoff, T., Valentine, S. A., Chen, G., Shi, T., Lengyel, J. A., Paroush, Z. and Courey, A. J. (1997). Conversion of dorsal from an activator to a repressor by the global corepressor Groucho. Genes Dev. 11, 2952-2957.

Duboule, D. (1994). Guidebook to the Homeobox Genes. Oxford, New York: Oxford University Press.

Emami, K. H. and Carey, M. (1992). A synergistic increase in potency of a multimerized VP16 transcriptional activation domain. EMBO J. 11, 50055012.

Fisher, J. P., Hope, S. A. and Hooper, M. L. (1989). Factors influencing the differentiation of embryonal carcinoma and embryo-derived stem cells. Exp. Cell Res. 182, 403-414.

Fofanova, O., Takamura, N., Kinoshita, E., Vorontsov, A., Vladimirova, V., Dedov, I., Peterkova, V. and Yamashita, S. (2000). MR imaging of the pituitary gland in children and young adults with congenital combined pituitary hormone deficiency associated with PROP1 mutations. Am. J. Roentgenol. 174, 555-559.

Gehring, W. J., Affolter, M. and Burglin, T. (1994). Homeodomain proteins. Annu. Rev. Biochem. 63, 487-526.

Germain, S., Howell, M., Esslemont, G. M. and Hill, C. S. (2000). Homeodomain and winged-helix transcription factors recruit activated Smads to distinct promoter elements via a common Smad interaction motif. Genes Dev. 14, 435-451.

Hanna-Rose, W. and Hansen, U. (1996). Active repression mechanisms of eukaryotic transcription repressors. Trends Genet. 12, 229-234.

Henry, G. L. and Melton, D. A. (1998). Mixer, a homeobox gene required for endoderm development. Science 281, 91-96.

Hermesz, E., Mackem, S. and Mahon, K. A. (1996). Rpx: a novel anteriorrestricted homeobox gene progressively activated in the prechordal plate, anterior neural plate and Rathke's pouch of the mouse embryo. Development 122, 41-52.

Jimenez, G., Paroush, Z. and Ish-Horowicz, D. (1997). Groucho acts as a corepressor for a subset of negative regulators, including Hairy and Engrailed. Genes Dev. 11, 3072-3082.

Jimenez, G., Verrijzer, C. P. and Ish-Horowicz, D. (1999). A conserved motif in goosecoid mediates groucho-dependent repression in Drosophila embryos. Mol. Cell Biol. 19, 2080-2087.

Latinkic, B. V. and Smith, J. C. (1999). Goosecoid and mix.1 repress Brachyury expression and are required for head formation in Xenopus. Development 126, 1769-1779.

Levine, M. and Manley, J. L. (1989). Transcriptional repression of eukaryotic promoters. Cell 59, 405-408.

Lin, Y. S., Carey, M. F., Ptashne, M. and Green, M. R. (1988). GAL4 derivatives function alone and synergistically with mammalian activators in vitro. Cell 54, 659-664.

Lu, Q. and Kamps, M. P. (1996). Structural determinants within Pbx1 that mediate cooperative DNA binding with pentapeptide containing Hox proteins: proposal for a model of a Pbx1-Hox-DNA complex. Mol. Cell Biol. 16, 1632-1640.

Mailhos, C., Andre, S., Mollereau, B., Goriely, A., Hemmati-Brivanlou, A. and Desplan, C. (1998). Drosophila Goosecoid requires a conserved heptapeptide for repression of paired-class homeoprotein activators. Development 125, 937-947.

McKnight, S. and Tjian, R. (1986). Transcriptional selectivity of viral genes in mammalian cells. Cell 46, 795-805.
Mead, P. E., Brivanlou, I. H., Kelley, C. M. and Zon, L. I. (1996). BMP-4responsive regulation of dorsal-ventral patterning by the homeobox protein Mix.1. Nature 382, 357-360.

Mountford, P., Zevnik, B., Duwel, A., Nichols, J., Li, M., Dani, C., Robertson, M., Chambers, I. and Smith, A. (1994). Dicistronic targeting constructs: reporters and modifiers of mammalian gene expression. Proc. Natl. Acad. Sci. USA 91, 4303-4307.

Netchine, I., Sobrier, M. L., Krude, H., Schnabel, D., Maghnie, M., Marcos, E., Duriez, B., Cacheux, V., Moers, A., Goossens, M. et al. (2000). Mutations in LHX3 result in a new syndrome revealed by combined pituitary hormone deficiency. Nat. Genet. 25, 182-186.

Parks, J. S., Brown, M. R., Hurley, D. L., Phelps, C. J. and Wajnrajch, M. P. (1999). Heritable disorders of pituitary development. J. Clin. Endocrinol. Metab. 84, 4362-4370.

Piper, D. E., Batchelor, A. H., Chang, C. P., Cleary, M. L. and Wolberger, C. (1999). Structure of a HoxB1-Pbx1 heterodimer bound to DNA: role of the hexapeptide and a fourth homeodomain helix in complex formation. Cell 96, 587-597.

Schier, A. F. and Gehring, W. J. (1992). Direct homeodomain-DNA interaction in the autoregulation of the fushi tarazu gene. Nature 356, 804807.

Smith, A. G., Heath, J. K., Donaldson, D. D., Wong, G. G., Moreau, J., Stahl, M. and Rogers, D. (1988). Inhibition of pluripotential embryonic stem cell differentiation by purified polypeptides. Nature 336, 688-690.

Smith, S. T. and Jaynes, J. B. (1996). A conserved region of engrailed, shared among all en-, gsc-, Nk1-, Nk2- and msh-class homeoproteins, mediates active transcriptional repression in vivo. Development 122, 3141-3150.

Sornson, M. W., Wu, W., Dasen, J. S., Flynn, S. E., Norman, D. J., O’Connell, S. M., Gukovsky, I., Carriere, C., Ryan, A. K., Miller, A. P. et al. (1996). Pituitary lineage determination by the Prophet of Pit-1 homeodomain factor defective in Ames dwarfism. Nature 384, 327-333.

Tada, M., Casey, E. S., Fairclough, L. and Smith, J. C. (1998). Bix1, a direct target of Xenopus T-box genes, causes formation of ventral mesoderm and endoderm. Development 125, 3997-4006.

Thomas, P. and Beddington, R. (1996). Anterior primitive endoderm may be responsible for patterning the anterior neural plate in the mouse embryo. Curr. Biol. 6, 1487-1496.

Thomas, P. Q., Dattani, M. T., Brickman, J. M., McNay, D., Warne, G., Zacharin, M., Cameron, F., Hurst, J., Woods, K., Dunger, D. et al. (2001). Heterozygous HESX1 mutations associated with isolated congenital pituitary hypoplasia and septo-optic dysplasia. Hum. Mol. Genet. 10, 39-45.

Tolkunova, E. N., Fujioka, M., Kobayashi, M., Deka, D. and Jaynes, J. B. (1998). Two distinct types of repression domain in engrailed: one interacts with the groucho corepressor and is preferentially active on integrated target genes. Mol. Cell Biol. 18, 2804-2814.

Treisman, J., Gonczy, P., Vashishtha, M., Harris, E. and Desplan, C. (1989). A single amino acid can determine the DNA binding specificity of homeodomain proteins. Cell 59, 553-562.

Valentine, S. A., Chen, G., Shandala, T., Fernandez, J., Mische, S., Saint, R. and Courey, A. J. (1998). Dorsal-mediated repression requires the formation of a multiprotein repression complex at the ventral silencer. Mol. Cell Biol. 18, 6584-6594.

Wales, J. K. and Quarrell, O. W. (1996). Evidence for possible Mendelian inheritance of septo-optic dysplasia. Acta Paediatr. 85, 391-392.

Wilson, D., Sheng, G., Lecuit, T., Dostatni, N. and Desplan, C. (1993). Cooperative dimerization of paired class homeo domains on DNA. Genes Dev. 7, 2120-2134.

Winnier, A. R., Meir, J. Y., Ross, J. M., Tavernarakis, N., Driscoll, M., Ishihara, T., Katsura, I. and Miller, D. M., 3rd (1999). UNC-4/UNC-37dependent repression of motor neuron-specific genes controls synaptic choice in Caenorhabditis elegans. Genes Dev. 13, 2774-2786.

Wolberger, C. (1996). Homeodomain interactions. Curr. Opin. Struct. Biol. 6, 62-68.

Xu, L., Lavinsky, R. M., Dasen, J. S., Flynn, S. E., McInerney, E. M., Mullen, T. M., Heinzel, T., Szeto, D., Korzus, E., Kurokawa, R. et al. (1998). Signal-specific co-activator domain requirements for Pit-1 activation. Nature 395, 301-306. 